\title{
Flood susceptibility mapping in Erythropotamos river basin with the aid of Remote Sensing and GIS
}

\author{
Christos Domakinis ${ }^{1, *}$, Antonios Mouratidis ${ }^{1}$, Kostas Voudouris ${ }^{1}$, \\ Theodore Astaras ${ }^{1}$, Maria Chara Karypidou ${ }^{2}$
}

\footnotetext{
${ }^{1}$ Aristotle University of Thessaloniki, Department of Environmental and Physical Geography, Greece

2 Aristotle University of Thessaloniki, Department of Meteorology and Climatology, Greece

* Corresponding author: cdomakin@yahoo.gr
}

\begin{abstract}
Erythropotamos is a tributary of river Evros and during the last decade its drainage basin flooded many times, causing extensive damage on properties. In order to assess flood susceptibility in the aforementioned study area, the inundated areas of floods that occurred in 2010, 2017 and 2018 were initially delineated with the aid of SAR (Synthetic Aperture Radar) imagery by applying an established flood delineation methodology. Subsequently, flood susceptibility mapping was conducted for the study area by applying the Analytical Hierarchy Process (AHP). Topographical, hydrological and meteorological factors were used and each one of them was classified into three (3) flood susceptibility categories (low, medium and high). The determination of the importance for each factor over the others, which is the main objective of this research, was decided according to the proportion of the 2010 inundated area, captured by ENVISAT/ASAR imagery, which intersected with each factor's high susceptibility class. Finally, the resulting flood susceptibility map was validated according with the inundated areas of the 2017 and 2018 flood events, captured by SENTINEL - 1 A/B imagery, indicating that approximately $60 \%$ of both of these areas intersected with the map's high susceptibility zone.
\end{abstract}

\section{KEYWORDS}

GIS; Susceptibility mapping; Analytical Hierarchy Process (AHP); floods; remote sensing

Received: 15 May 2019

Accepted: 7 May 2020

Published online: 31 July 2020

Domakinis, C., Mouratidis, A., Voudouris, K., Astaras, T., Karypidou, M. C. (2020): Flood susceptibility mapping in Erythropotamos river basin with the aid of Remote Sensing and GIS. AUC Geographica 55(2), 149-164 https://doi.org/10.14712/23361980.2020.11

(C) 2020 The Authors. This is an open-access article distributed under the terms of the Creative Commons Attribution License (http://creativecommons.org/licenses/by/4.0). 


\section{Introduction}

Floods can potentially cause fatalities, displacement of people and damage to the environment, to severely compromise economic development and to undermine the economic activities of every community that suffers the effects of these destructive environmental hazards (Patrikaki et al. 2018; Zhong et al. 2018; Birkholz et al. 2014; Mouratidis and Sarti 2013; Yésou et al. 2013; Astaras et al. 2011). During the last decade, such phenomena have also plagued Greece, with their majority occurring in the eastern part of the region of Thrace (Kazakis et al. 2015; Nikolaidou et al. 2015; Mouratidis 2011; Mouratidis et al. 2011). Most such cases are attributed to the river Evros, which is the natural borderline between Greece and Turkey, and, along with its tributaries, has burst its banks on several occasions during the aforementioned time period. Erythropotamos is one of Evros' tributaries and although, in many occasions, flood phenomena have been observed within its river basin, there is a lack of flood hazard assessment studies referring to this catchment.

During the last few decades, advances in remote sensing and GIS have helped flood hazard assessment to become more effective. Inundation and susceptibility mapping are among the main procedures that flood hazard assessment follows, in order to achieve its goals.

Regarding inundation mapping, SAR systems are particularly suitable, thanks to the synoptic view, the capability to operate in almost all-weather conditions and during both day-time and night-time, as well as the sensitivity of the microwave radiation to water (Pierdicca et al. 2013). Furthermore, various methods have been used within the literature to delineate flood water from SAR data. Change detection highlights the temporal changes in land cover by comparing the flood scene to a previous dry image (Li et al. 2018; Psomiadis 2016; Schlaffer et al. 2015). The difference between the images can be combined with other image segmentation techniques to identify areas producing an unusually low backscatter response, improving the reliability of the flood delineation when compared to the single image methodologies (Matgen et al. 2011).

Concerning flood susceptibility mapping, according to the current literature, the contemporary trend involves mostly the creation of ensemble models, which are based on the combination of

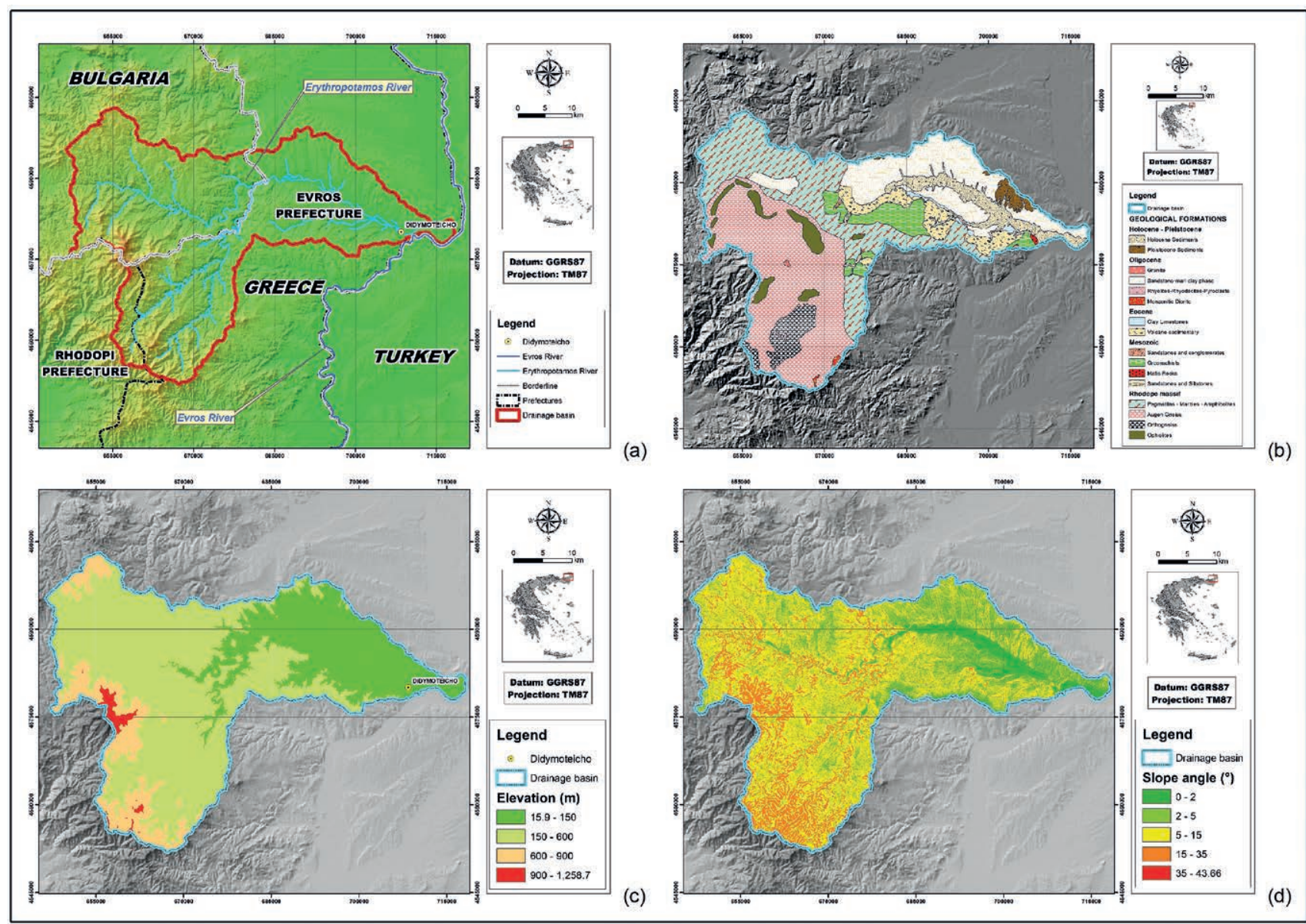

Fig. 1 a) Location of the study area (drainage basin of Erythropotamos), b) Geological formations within the drainage basin of Erythropotamos river (CoG 1989, I.G.M.E. 2002), c) Spatial distribution of elevation within the catchment of Erythropotamos river (E.E.A. 2017) and d) Spatial distribution of slope angle values within the drainage basin of Erythropotamos river. 
different data-driven (machine learning), statistical or multi-criteria methods. This approach aims in achieving higher accuracy of the delineated susceptibility zones, in comparison with the flood susceptibility mapping methodologies that employ a single method or model (Costache et al. 2020; Kanani-Sadat et al. 2019; Wang et al. 2019; Khosravi et al. 2016). However, there is a plethora of methodologies that can be used in flood susceptibility assessment, such as statistical and data-driven approaches (Ettinger et al. 2016; Nandi et al. 2016; Tehrany et al. 2015; Tehrany et al. 2014; Pulvirenti et al. 2011). Among them, the analytic hierarchy process (AHP) (Kazakis et al. 2015; Stefanidis and Stathis 2013) is considered as the most widely used and, because of its simplicity, continues to be popular even in recent works (Lyu et al. 2018; Seejata et al. 2018; Tang et al. 2018). Additionally, this methodology has proved many times that it can handle sparse or poor quality data and that it can operate efficiently in regional studies (Chen et al. 2015, 2013; Wang et al. 2011).

The main aim of this research is to introduce a methodology that deals with the subjectivity that involves the determination of the hierarchy of factors in flood susceptibility mapping with the use of AHP. To this end, the proposed methodology employed the results of SAR-based inundation mapping that delineated the flood extent of the 2010 flood. Specifically, the hierarchy between the flood susceptibility factors was determined according to the proportion of the aforementioned inundated areas that intersected with each factor's high susceptibility class.
Tab. 1 Distribution of elevation into categories according to Dikau's classification (Dikau 1989).

\begin{tabular}{|l|l|c|c|}
\hline Elevation & Description & Area $\left(\mathrm{km}^{2}\right)$ & Percent (\%) \\
\hline$<150$ & Lowland & 429.6 & 26.543 \\
\hline $150-600$ & Hilly & 969.1 & 59.876 \\
\hline $600-900$ & Semi-mountainous & 197.3 & 12.190 \\
\hline $900>$ & Mountainous & 22.5 & 1.390 \\
\hline
\end{tabular}

Tab. 2 Slope angle categorization within the study area according to Demek's classification (Demek 1972).

\begin{tabular}{|l|l|c|c|}
\hline $\begin{array}{l}\text { Slope Angle } \\
\left({ }^{\circ}\right)\end{array}$ & Description & Area $\left(\mathrm{km}^{2}\right)$ & Percent (\%) \\
\hline $0-2$ & Plain to slightly sloping & 147.5 & 9.11 \\
\hline $2-5$ & Gently inclined & 390.3 & 24.11 \\
\hline $5-15$ & Strongly inclined & 864.9 & 53.44 \\
\hline $15-35$ & Steep & 215.7 & 13.33 \\
\hline$>35$ & Precipitous & 0.1 & 0.01 \\
\hline
\end{tabular}

\section{Location of the study area}

Erythropotamos is a tributary of Evros River, which is the longest river that runs solely in the interior of the Balkans, and its catchment covers an extent of $1,618.5 \mathrm{~km}^{2}$. The largest part of its river basin belongs to Greece and particularly to the geographic region of Thrace in Northern Greece, while the rest of its drainage basin belongs to Bulgaria (Figure 1a).

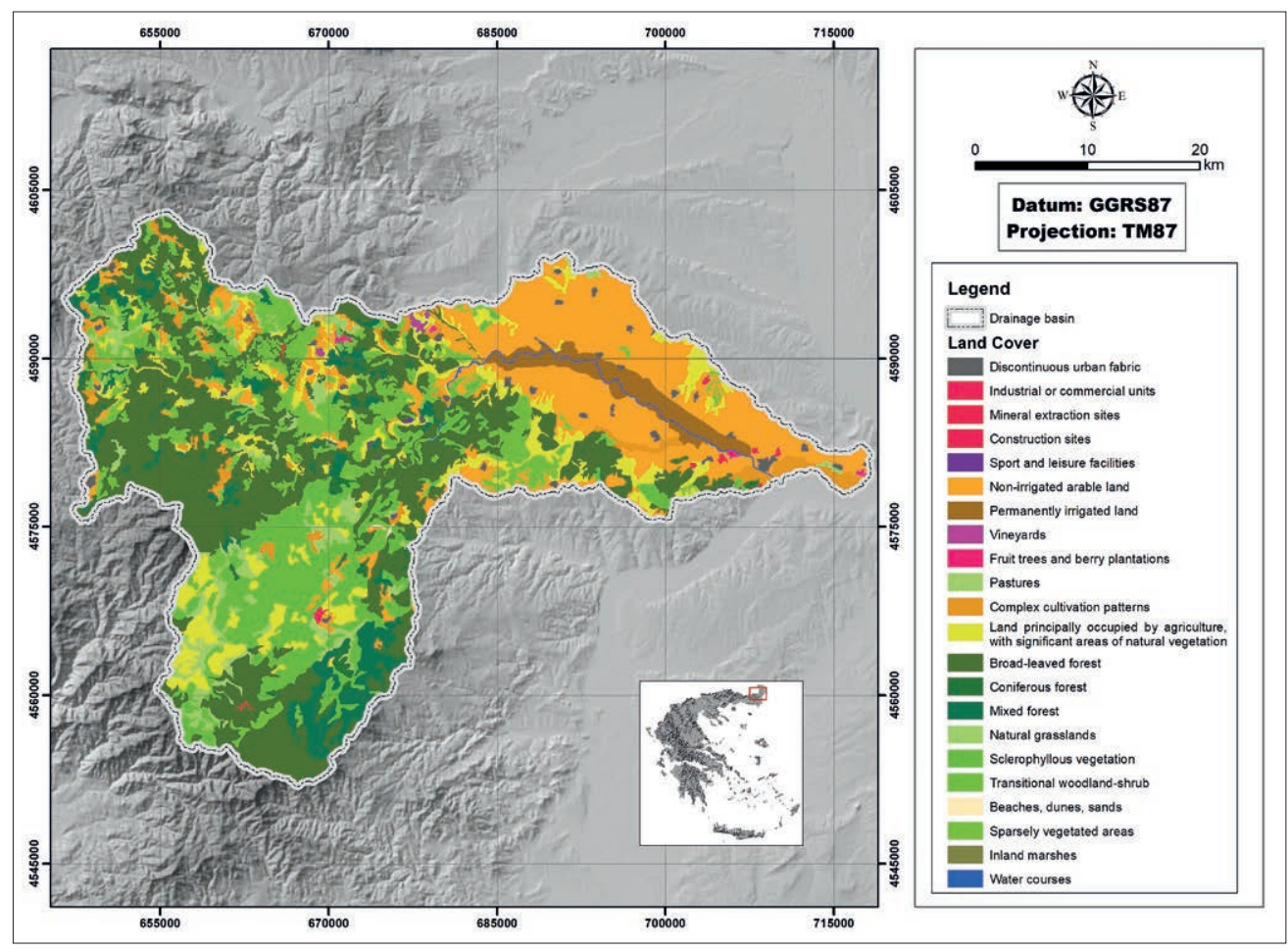

Fig. 2 Spatial distribution of land cover in the catchment of Erythropotamos river (Copernicus 2017). 


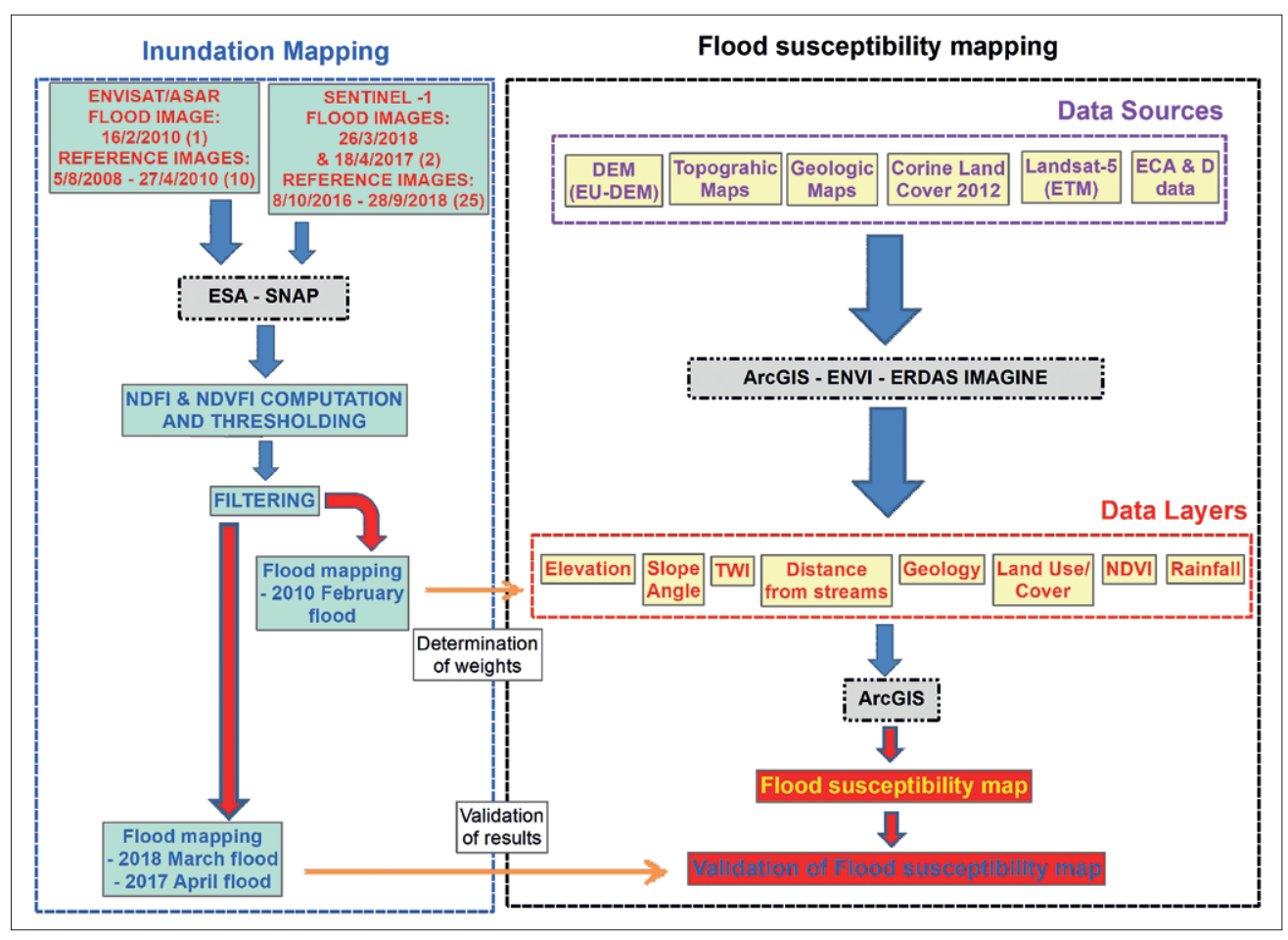

Fig. 3 General flowchart of the applied methodology.

Regarding administrative distribution within national borders, the Greek part of Erythropotamos' river basin belongs to the Prefectures of Evros and Rhodopi.

The drainage basin of Erythropotamos River belongs to both the Circum - Rhodope geotectonic zone and the Rhodope massif. The geological formation that covers the largest part of the study area consists of orthogneissess and augen gneisses (Figure 1b).

Elevation in the drainage basin of Erythropotamos river ranges from $16 \mathrm{~m}$ to about $1,258 \mathrm{~m}$ above mean sea level (M.S.L.), and the largest part of the study area can be described as hilly according to Dikau's classification (Dikau 1989) (Figure 1c and Table 1). Additionally, the spatial distribution of slope angle values within the study area, indicates that most of its terrain belongs to the strongly inclined category $\left(5^{\circ}-15^{\circ}\right)$ according to Demek's classification of slope angles (Demek 1972) (Figure 1d and Table 2).

Finally, based on information provided by the data layer of Corine Land Cover 2012 (Copernicus 2017),

Tab. 3 Distribution of Land Cover within the river basin of Erythropotamos according to Corine Land Cover 2012 (Copernicus 2017).

\begin{tabular}{|l|r|c|}
\hline Land Cover & Area $\left(\mathrm{km}^{2}\right)$ & Percent $(\%)$ \\
\hline Artificial surfaces & 18.4 & 1.137 \\
\hline Agricultural areas & 586.2 & 36.219 \\
\hline Forest and semi natural areas & 1007.9 & 62.274 \\
\hline Wetlands & 0.1 & 0.006 \\
\hline Water bodies & 5.9 & 0.365 \\
\hline
\end{tabular}

which, instead of the Corine Land Cover 2018 (Copernicus 2020) data layer, is chronologically closer to the gauged 2010 flood event, the catchment of Erythropotamos River is dominated by forests and semi natural areas (Figure 2). Along with agricultural areas, these two land cover categories occupy approximately the $98 \%$ of the total extent of the study area (Table 3 ).

\section{Materials and methodology}

The materials that were used and the methodology that was followed in order to achieve the aims of this study can be divided into two parts. The first involves inundation mapping with the use of SAR images, while the second part is concerned with flood susceptibility mapping with the use of AHP. The general flowchart is given in Figure 3.

\subsection{Inundation mapping with SAR imagery}

Eleven ENVISAT/ASAR and twenty seven SENTINEL - 1 A/B images of VV (Vertical transmit - Vertical receive) polarization were used to map the flood extents of the February 2010, April 2017 and March 2018 flood events. Their detailed product characteristics appear on Table 4.

The aforementioned SAR images were pre-processed with the aid of ESA's SAR satellite image analysis software SNAP (Sentinel Application Platform). Initially, they were calibrated to $\sigma^{\circ}$ backscatter coefficient values and despeckled using a $3 \times 3$ Gamma map filter. Regarding the co-registration step, the SAR 
Tab. 4 Product information of ENVISAT/ASAR and SENTINEL $1 \mathrm{~A} / \mathrm{B}$ imagery.

\begin{tabular}{|l|l|l|}
\hline Satellite & ENVISAT & SENTINEL - 1 \\
\hline Dates & $\begin{array}{l}\text { Flood image: } \\
16 / 2 / 2010(1) \\
\text { Reference images: } \\
5 / 8 / 2008 \text { to } \\
27 / 4 / 2010(10)\end{array}$ & $\begin{array}{l}\text { Flood images: } 18 / 4 / 2017 \\
\text { Reference images: } \\
8 / 10 / 2016 \text { to } \\
28 / 9 / 2018(25)\end{array}$ \\
\hline $\begin{array}{l}\text { Spatial } \\
\text { Resolution }\end{array}$ & $11.1 \mathrm{~m} \times 11.1 \mathrm{~m}$ & $8.8 \mathrm{~m} \times 8.8 \mathrm{~m}$ \\
\hline Pass & Ascending & Descending \\
\hline Mode & N/A & IW \\
\hline Type & N/A & GRD \\
\hline Level & 1 & 1 \\
\hline Polarization & VV & VV \\
\hline Relative Orbit & 14 & 109 \\
\hline
\end{tabular}

images were co-registered with the use of EU-DEM, which is the Digital Surface Model (DSM) of European Environment Agency (EEA) member and cooperating countries that represents the first surface as illuminated by the sensors. It is a hybrid product based on SRTM and ASTER GDEM data fused by a weighted averaging approach (EEA 2017). Its horizontal spatial resolution is 1 arc second (approximately $25 \mathrm{~m}$ ), while its absolute and relative vertical accuracy are $3.6 \mathrm{~m}$ and $5.3 \mathrm{~m}$, respectively (Mouratidis et al. 2019).

The Change Detection And Thresholding (CDAT) methodology by Cian et al. (2018), based on the work of Long et al. (2014), was applied in order to delineate the inundated areas of the aforementioned flood events. This procedure involved the calculation of the Normalized Difference Flood Index (NDFI) and the Normalized Difference Flood in low Vegetation Index (NDFVI), which are based on the multi-temporal statistical analysis of two sets of images, one containing only the images before or after the event, and another one containing images both before or after the event and during the occurrence of the event. NDFI categorizes as flooded only areas that are temporarily covered by water, excluding permanent water bodies and non-water land cover classes. On the other hand, NDFVI was used in order to detect shallow water in low vegetation.

According to Cian et al. (2018) NDFI values that are greater than 0.7 and NDFVI values that are greater than 0.75 can be used to delineate inundated areas in open land and in low vegetation respectively. However, the resulting flooded areas require further processing according to the following criteria:

1. Flooded areas with extent smaller than the size of 10 pixels in NDFI and NDFVI images were excluded because they can be considered as spurious (Cian et al. 2018).

2. Pixels with $\sigma_{o(\text { mean })}$ values less than 0.015 ( $\sigma_{o \text { (mean) }}$ $<0.015$ ), which correspond to permanent water bodies, and pixels with $\sigma_{\mathrm{o}(\min )}$ values greater than $0.03\left(\sigma_{o(\min )}>0.03\right)$ that represent pixels that consistently decrease their backscatter during the flood, indicating that something happened, but not enough to reach a $\sigma_{o(\min )}$ value typical of water pixels, have to be filtered out from the resulting inundation maps (Cian et al. 2018).

Moreover, the adverse weather conditions during the 2010, 2017 and 2018 floods prevented satellite optical imagery and aerial vehicles from capturing the extents of the corresponding floods and thus validation of their SAR-based inundation mapping results was not feasible.

\subsection{Flood susceptibility mapping with the use of AHP and with the aid of GIS and satellite imagery}

The compilation of the susceptibility map can be achieved by conducting multi-criteria analysis (MCA), which involves the selection of criteria whose weights will be determined via the AHP. In this process, the selection of criteria is very important. A plethora of criteria has been used in previous research on flood susceptibility mapping (Hong et al. 2018; Lyu et al.

Tab. 5 Details regarding the data from which each factor was compiled.

\begin{tabular}{|l|l|l|l|l|}
\hline Primary input data & $\begin{array}{l}\text { Original } \\
\text { format }\end{array}$ & $\begin{array}{l}\text { Map scale or spatial } \\
\text { resolution }\end{array}$ & Source & Derived map \\
\hline EU-DEM & Raster & $25 \mathrm{~m} \times 25 \mathrm{~m}$ & EEA & Elevation \\
\hline EU-DEM & Raster & $25 \mathrm{~m} \times 25 \mathrm{~m}$ & EEA & Slope Angle \\
\hline Corine Land Cover 2012 & Vector & Better than $100 \mathrm{~m}$ & Copernicus & Land Cover \\
\hline EU-DEM & Raster & $25 \mathrm{~m} \times 25 \mathrm{~m}$ & EEA & Drainage Density \\
\hline EU-DEM & Raster & $25 \mathrm{~m} \times 25 \mathrm{~m}$ & EEA & TWI \\
\hline $\begin{array}{l}\text { 1) Geologic Map of SE } \\
\text { Rhodope- Thrace } \\
\text { 2) Geologic map of Bulgaria }\end{array}$ & Raster & $\begin{array}{l}\text { 1) } 1: 200,000 \\
\text { 2) } 1: 50,000\end{array}$ & $\begin{array}{l}\text { 1) } 1: 200,000 \text { Institute of Geology and } \\
\text { Mineral Exploration (IGME) of Greece } \\
\text { 2) 1:50,000 Committee of Geology (CoG) }\end{array}$ & Geology \\
\hline WorldClim & Raster & $825 \mathrm{~m} \times 825 \mathrm{~m}$ & Fick et al. 2017 & Rainfall \\
\hline EU-DEM & Raster & $25 \mathrm{~m} \times 25 \mathrm{~m}$ & EEA & $\begin{array}{l}\text { Distance from } \\
\text { Streams }\end{array}$ \\
\hline
\end{tabular}


2018; Seejata et al. 2018; Tang et al. 2018; Xiao et al. 2018; Zhao et al. 2018; Kazakis et al. 2015). Their main characteristics being that they should be connected with the physical process of the flood generation mechanism, they can be measured or quickly calculated for the whole study area and that they ought to have simple interpretability (Papaioannou et al. 2015).

According to Xiao et al. (2018) and Zhao et al. (2018), the factor's effect on the flood hazard and data availability, three types of indicators were considered in the present research, i.e. topographical, hydrological and meteorological. Specifically, topographical indicators (Xiao et al. 2018) provide information of the flow or stagnating of the water on the ground due to the impact of the terrain. In the current study they consist of elevation, slope angle and drainage density. On the other hand, hydrological indicators (Xiao et al. 2018) provide information of the intercept, infiltration and accumulation of the water and the river network. They consist of Topographic Wetness Index (TWI), distance from streams, land cover and geology. Finally, the meteorological indicators (Zhao et al. 2018) provide information on the spatial distribution of precipitation in the study area and were represented by the annual total rainfall.

The input data, their original format, the source from which the input data originated and their map scale or spatial resolution for each factor are synoptically presented in the following table (Table 5).

\subsubsection{Topographical indicators}

\subsubsection{Elevation}

Elevation is considered as an important factor for floods, because flood-prone areas tend to occupy drainage basin areas with low elevation values. The data layer of elevation was derived from EU-DEM.

\subsubsection{Slope Angle}

The slope angle data layer was produced by the EU-DEM data layer with the aid of raster-processing routines. Slope angle is also an important factor when it comes to discerning flood-prone areas, because areas in a river basin that occupy flat terrain surfaces tend to flood more easily than areas with more steep surface terrain.

\subsubsection{Drainage Density}

The drainage density is defined as the total stream length per unit area, which can be calculated as shown in the following equation (1) (Zhou et al. 2014):

$$
D D=\frac{1}{S} \sum_{i} L_{i}^{S}
$$

$D D$ stands for drainage density, while $S$ represents the area of the grid and $L_{i}^{S}$ represents the length of river $i$ within the grid. Areas with high drainage density indicate high flood susceptibility.

\subsubsection{Hydrological indicators}

\subsubsection{Topographic Wetness Index (TWI)}

This index according to Miliaresis (2011) belongs to the indices of soil erosion, since it is used to relate the effects of runoff with geomorphometry. It is used in order to assess soil moisture and it is defined by the Beven and Kirkby (1979) equation:

$$
T W I=\ln \left(\frac{a}{\tan (\beta)}\right)
$$

In equation (2), $\alpha$ stands for the local upslope area draining through a certain point per unit contour length and $\tan (\beta)$ is the local slope in radians. High values of TWI indicate areas more susceptible to flooding.

\subsubsection{Distance from streams}

The drainage network of the drainage basin of Erythropotamos river has been produced by the EU-DEM data layer with the use of raster-processing routines (Voudouris et al. 2007). Furthermore, the distance from the streams of the drainage network data layer was compiled through the use of geoprocessing buffer routines. This factor is crucial to flood susceptibility mapping, because areas that are closer to streams are more likely to be inundated during a flood event.

\subsubsection{Geology}

The synoptic geologic map of SE Rhodope - Thrace from the Institute of Geology and Mineral Exploration (IGME) of Greece, at a scale of 1:200,000 (I.G.M.E. 2002), was used in order to produce the part of the data layer that belongs to Greece. Accordingly, the geologic map of Bulgaria from the Department of Geophysical Prospecting and Geological Mapping of the Committee of Geology (CoG 1989), at a scale of 1:50,000, was used in order to produce the part of the data layer that belongs to Bulgaria.

Geology is considered a significant factor in determining flood-prone areas, because impermeable geological formations favor surface runoff. On the other hand, permeable geological formations favor infiltration.

\subsubsection{Land Cover}

The data layer of Corine Land Cover 2012 (Copernicus 2017) was used to determine the land cover classes within the limits of the study area. It is worth mentioning that Corine Land Cover 2012 was chosen over Corine Land Cover 2018 (Copernicus 2020), because it depicts more closely the surface relief's land cover conditions during the 2010 flood, which was gauged by the station on Didymoteicho's bridge. Additionally, regarding the catchment of Erythropotamos River, the differences between the aforementioned data layers are insignificant since they cover a total extent of approximately $2 \mathrm{~km}^{2}$. Vieux (2004) correlated land cover classes with Manning's n roughness 
coefficient (Table 6), which participates in Manning's formula:

$$
V=\frac{1}{n} A r^{\frac{2}{3}} S^{\frac{1}{2}}
$$

In equation (3), $V$ stands for discharge/flow $\left(\mathrm{m}^{3} / \mathrm{s}\right)$, $n$ is Manning's roughness coefficient, $A$ is the "wetted" cross-sectional area $\left(\mathrm{m}^{2}\right), r$ stands for the hydraulic radius and $S$ is the slope of hydraulic grade or the linear head loss $(\mathrm{m} / \mathrm{m})$. Moreover, Manning's $n$ roughness coefficient is inversely proportional to discharge, which means that low Manning's $n$ values correspond to high discharge values. In that way, areas susceptible to floods can be related to low Manning's $n$ values.

\subsubsection{Meteorological indicators}

\subsubsection{Rainfall}

The annual total rainfall layer was derived using raw data that were retrieved from the WorldClim database (Fick et al. 2017). The raw data involve monthly precipitation totals, which refer to the climatological period 1970-2000 and are available as an approximately 30 seconds by 30 seconds (approximately 824 by $824 \mathrm{~m}$ ) grid (Fick et al. 2017). The total annual precipitation layer was constructed by summing all 12 monthly precipitation totals with the aid of map algebra. Subsequently, the aforementioned rainfall layer was converted to a point shapefile, from which the final rainfall data layer, with a spatial resolution of $25 \mathrm{~m}$, was derived. The downscaling of the original WorldClim layer ( $824 \times 824 \mathrm{~m}$ grid resolution) to the layer that was eventually used in the current analysis ( $25 \times 25 \mathrm{~m}$ grid resolution), was performed by employing the universal kriging spatial interpolation method (Li et al. 2014). The interpolated values were the total annual precipitation values obtained at each point of the original WorldClim grid. The auxiliary variables used were elevation, slope, aspect and distance from the sea. The elevation data used was the EU-DEM obtained from the COPERNICUS Land Monitoring Services data portal (EEA 2017) and is provided on a 25 by $25 \mathrm{~m}$ grid. Slope and aspect were derived from the EU-DEM using the available raster-processing routines. Distance from the sea was also computed, by applying proximity analysis routines, at a spatial resolution of $25 \mathrm{~m}$. Areas with high

Tab. 6 Manning's $n$ roughness coefficients for certain land cover types according to Vieux (2004).

\begin{tabular}{|l|c|}
\hline Land Cover & Manning's $n$ coefficient \\
\hline Artificial surfaces & 0.015 \\
\hline Agricultural areas & 0.035 \\
\hline Forest and semi natural areas & 0.100 \\
\hline Wetlands & 0.700 \\
\hline Water bodies & 0.030 \\
\hline
\end{tabular}

annual precipitation sums were considered as more prone to flooding.

\subsection{Analytical Hierarchy Process (AHP)}

\subsubsection{Determination of flood susceptibility classes for each factor}

In order to apply the AHP methodology, which was introduced by Saaty (1980), the data layer of each factor was classified into three classes according to how prone each one of these classes was to flooding. Classes that are highly susceptible to flooding were assigned a rating of three (3), while those that are of medium susceptibility were assigned a rating of two (2) and those of low susceptibility were assigned a rating of one (1).

\subsubsection{Determination of the hierarchy between \\ the flood susceptibility factors with the aid of the results of SAR-based inundation mapping} Having to deal with the subjectivity that often accompanies this step of AHP, the importance of each factor was determined according to the proportion of the inundated areas of the 2010 flood event (total area of $6.84 \mathrm{~km}^{2}$ for both open water and shallow water in low vegetation) that intersected with each factor's high susceptibility class (Figure 4 and Table 7). This concept was based on the idea that a SAR image that is taken during a flood indicates the areas where flood water is concentrated. Moreover, the factors or indicators of flood susceptibility all coexist in these areas and it is known how each factor influences floods. For example it is known that, regarding e.g. slope angle, flat areas tend to flood more easily. Thus, the areas where flood water is concentrating are those where the most favourable conditions for most factors coexist, i.e. where the high susceptibility classes for most factors or indicators intersect. Subsequently, the more a high susceptibility class of a factor or indicator is encountered in inundated areas, the more influential this factor or indicator is in terms of flood susceptibility.

Tab. 7 Proportion of the total inundated area of the 2010 flood event that intersects with each factor's high susceptibility class.

\begin{tabular}{|l|c|c|}
\hline Factor & $\begin{array}{c}\text { Extent of inundated } \\
\text { area }\left(\mathrm{km}^{2}\right)\end{array}$ & $\begin{array}{c}\text { Percent } \\
\text { ratio (\%) }\end{array}$ \\
\hline Land Cover & 0.15 & 2.19 \\
\hline TWI & 0.12 & 1.75 \\
\hline Geology & 0.39 & 5.70 \\
\hline Distance from streams & 3.44 & 50.29 \\
\hline Rainfall & 0.01 & 0.15 \\
\hline Slope Angle & 5.59 & 81.73 \\
\hline Drainage Density & 0.99 & 14.47 \\
\hline Elevation & 6.66 & 97.37 \\
\hline
\end{tabular}



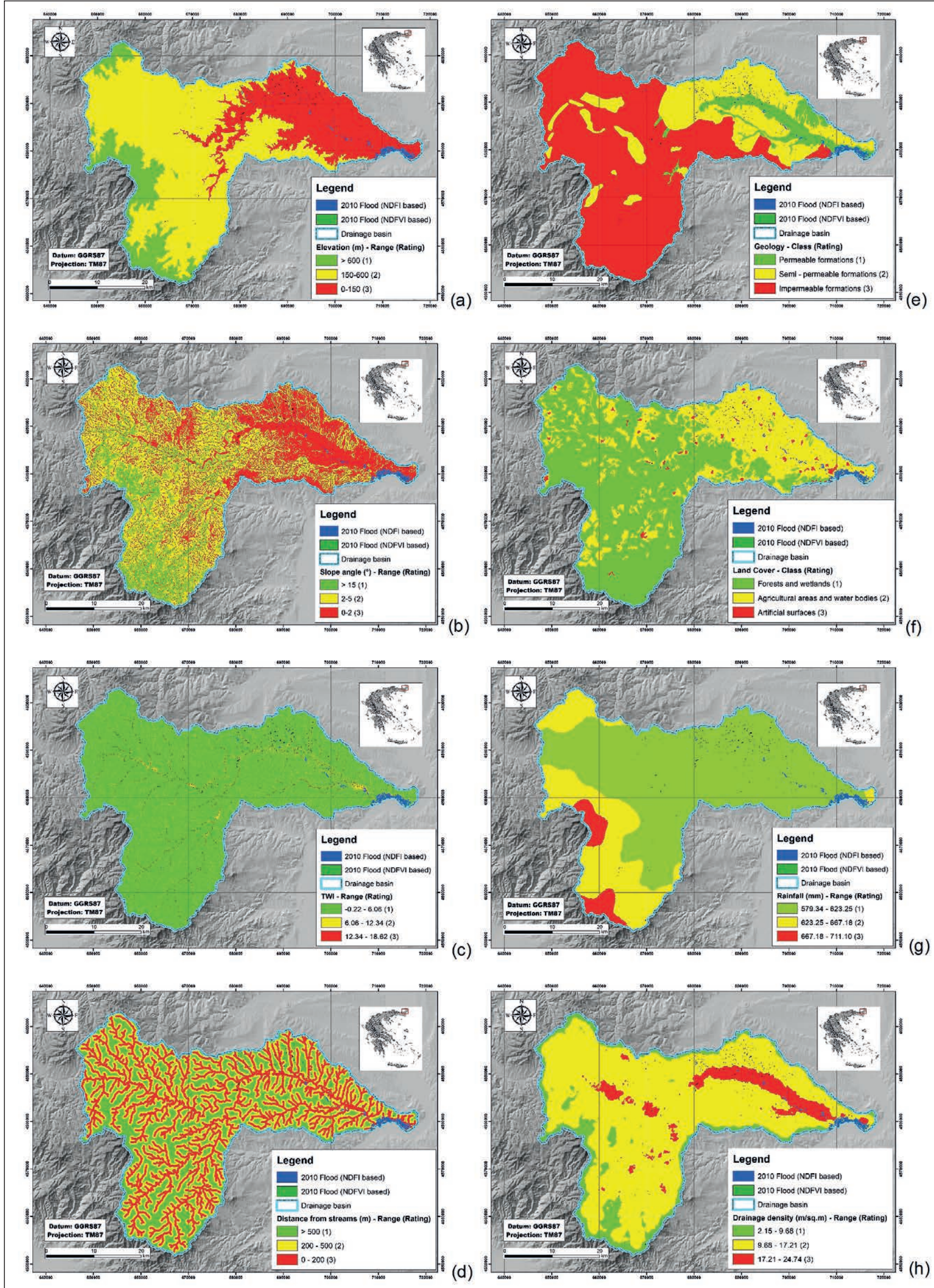

Fig. 4 The data layer of the inundated areas of the 2010 flood event has been superimposed upon the flood susceptibility classes of the factors' data layers: a) Elevation, b) Slope angle, c) TWI, d) Distance from streams, e) Geology, f) Land cover, g) Rainfall and h) Drainage density. 
Tab. 8 Pairwise comparison of the factors that affect flood susceptibility.

\begin{tabular}{|c|c|c|c|c|c|c|c|c|}
\hline & Elevation & $\begin{array}{l}\text { Slope } \\
\text { angle }\end{array}$ & $\begin{array}{l}\text { Distance } \\
\text { from } \\
\text { streams }\end{array}$ & $\begin{array}{l}\text { Drainage } \\
\text { Density }\end{array}$ & Geology & $\begin{array}{l}\text { Land } \\
\text { Cover }\end{array}$ & TWI & Rainfall \\
\hline Elevation & 1 & 2 & 3 & 4 & 5 & 6 & 7 & 8 \\
\hline Slope angle & $1 / 2$ & 1 & 2 & 3 & 4 & 5 & 6 & 7 \\
\hline Distance from streams & $1 / 3$ & $1 / 2$ & 1 & 2 & 3 & 4 & 5 & 6 \\
\hline Drainage Density & $1 / 4$ & $1 / 3$ & $1 / 2$ & 1 & 2 & 3 & 4 & 5 \\
\hline Geology & $1 / 5$ & $1 / 4$ & $1 / 3$ & $1 / 2$ & 1 & 2 & 3 & 4 \\
\hline Land Cover & $1 / 6$ & $1 / 5$ & $1 / 4$ & $1 / 3$ & $1 / 2$ & 1 & 2 & 3 \\
\hline TWI & $1 / 7$ & $1 / 6$ & $1 / 5$ & $1 / 4$ & $1 / 3$ & $1 / 2$ & 1 & 2 \\
\hline Rainfall & $1 / 8$ & $1 / 7$ & $1 / 6$ & $1 / 5$ & $1 / 4$ & $1 / 3$ & $1 / 2$ & 1 \\
\hline Total & 2.718 & 4.593 & 7.5 & 11.28 & 16.08 & 21.83 & 28.5 & 36 \\
\hline
\end{tabular}

Tab. 9 Calculation of the factor weights with the use of the arithmetic mean method.

\begin{tabular}{|c|c|c|c|c|c|c|c|c|c|}
\hline & Elevation & $\begin{array}{l}\text { Slope } \\
\text { angle }\end{array}$ & $\begin{array}{c}\text { Distance } \\
\text { from } \\
\text { streams }\end{array}$ & $\begin{array}{l}\text { Drainage } \\
\text { Density }\end{array}$ & Geology & $\begin{array}{l}\text { Land } \\
\text { Cover }\end{array}$ & TWI & Rainfall & Mean \\
\hline Elevation & 0.368 & 0.435 & 0.403 & 0.355 & 0.311 & 0.275 & 0.246 & 0.222 & $0.327(32.7 \%)$ \\
\hline Slope angle & 0.184 & 0.218 & 0.268 & 0.266 & 0.249 & 0.229 & 0.211 & 0.194 & $0.227(22.7 \%)$ \\
\hline $\begin{array}{l}\text { Distance } \\
\text { from streams }\end{array}$ & 0.123 & 0.109 & 0.134 & 0.177 & 0.187 & 0.183 & 0.175 & 0.167 & $0.157(15.7 \%)$ \\
\hline $\begin{array}{l}\text { Drainage } \\
\text { Density }\end{array}$ & 0.092 & 0.073 & 0.067 & 0.089 & 0.124 & 0.137 & 0.140 & 0.139 & $0.108(10.8 \%)$ \\
\hline Geology & 0.074 & 0.054 & 0.045 & 0.044 & 0.062 & 0.092 & 0.105 & 0.111 & $0.073(7.32 \%)$ \\
\hline Land Cover & 0.061 & 0.044 & 0.034 & 0.030 & 0.031 & 0.046 & 0.070 & 0.083 & $0.050(5 \%)$ \\
\hline TWI & 0.053 & 0.036 & 0.027 & 0.022 & 0.021 & 0.023 & 0.035 & 0.056 & $0.034(3.4 \%)$ \\
\hline Rainfall & 0.046 & 0.031 & 0.022 & 0.018 & 0.016 & 0.015 & 0.018 & 0.028 & $0.024(2.4 \%)$ \\
\hline
\end{tabular}

The 2010 flood extent was chosen for that purpose, because the measurements from the gauging station on Didymoteicho's bridge confirmed that during the date and time that the ENVISAT/ASAR's flood image was taken on $16 / 2 / 2010$, Erythropotamos indeed flooded. Additionally, ENVISAT/ASAR's imagery has lower spatial resolution when compared with SENTINEL-1 A/B imagery. Since the aforementioned gauging station went out of order in 2012, the only way to collect information for the 2017 and 2018 flood events was to rely on statements from members of the Department of Civil Protection of the region of Evros (C. Papapostolou, Department of Civil Protection of the region of Evros, personal communication, 2018).

\subsubsection{Pairwise comparison between the flood susceptibility factors and determination \\ of their weights with the use of the arithmetic mean method}

The factors were paired with each other and following that, each factor was given an arithmetic value between 1 and 8, according to its significance, in agreement with Table 7, when compared to the other factor, with which it formed the pair (Table 8). In the resulting matrix table, an arithmetic value of 8 indicates that a row factor is much more significant than the corresponding column factor with which it has been compared, while an arithmetic value of 1 means that both factors are equally significant. After the completion of Table 8, the arithmetic mean method has been applied to its results and the weights for each factor were calculated (Table 9).

To sum up, Table 10 presents synoptically the factors, the classes of flood susceptibility into which they were classified, the rating that was assigned for each class and the weight that was calculated for each factor via the application of AHP methodology (Kazakis et al. 2015).

\subsubsection{Consistency ratio}

In order to check the consistency of the eigenvector matrix of AHP, the consistency ratio was calculated according to the following formula:

$$
C R=\frac{C I}{R I}
$$

In mathematic formula (4), $C R$ stands for consistency ratio, $C I$ stands for consistency index, and $R I$ 
Tab. 10 Synoptic table presenting the factors, their flood susceptibility classes, the rating that was assigned for each class and the weight for each factor that was assigned through AHP methodology.

\begin{tabular}{|c|c|c|c|}
\hline Factor & Class & Rating & Weight \\
\hline \multirow{3}{*}{$\begin{array}{l}\text { Elevation } \\
(\mathrm{m})\end{array}$} & $>600$ & 1 & \multirow{3}{*}{0.327} \\
\hline & $150-600$ & 2 & \\
\hline & $0-150$ & 3 & \\
\hline \multirow{3}{*}{$\begin{array}{l}\text { Slope angle } \\
\left({ }^{\circ}\right)\end{array}$} & $>15$ & 1 & \multirow{3}{*}{0.227} \\
\hline & $2-5$ & 2 & \\
\hline & $0-2$ & 3 & \\
\hline \multirow{3}{*}{$\begin{array}{l}\text { Distance } \\
\text { from } \\
\text { streams } \\
\text { (m) }\end{array}$} & $>500$ & 1 & \multirow{3}{*}{0.157} \\
\hline & $200-500$ & 2 & \\
\hline & $0-200$ & 3 & \\
\hline \multirow{3}{*}{$\begin{array}{l}\text { Drainage } \\
\text { density } \\
\left(\mathrm{m} / \mathrm{m}^{2}\right)\end{array}$} & $2.15-9.68$ & 1 & \multirow{3}{*}{0.108} \\
\hline & $9.68-17.21$ & 2 & \\
\hline & $17.21-24.74$ & 3 & \\
\hline \multirow{3}{*}{ Geology } & Permeable formations & 1 & \multirow{3}{*}{0.073} \\
\hline & Semi - permeable formations & 2 & \\
\hline & Impermeable formations & 3 & \\
\hline \multirow{3}{*}{$\begin{array}{l}\text { Land } \\
\text { Cover }\end{array}$} & Forests and wetlands & 1 & \multirow{3}{*}{0.050} \\
\hline & Agricultural areas and water bodies & 2 & \\
\hline & Artificial surfaces & 3 & \\
\hline \multirow{3}{*}{ TWI } & $-0.22-6.06$ & 1 & \multirow{3}{*}{0.034} \\
\hline & $6.06-12.34$ & 2 & \\
\hline & $12.34-18.62$ & 3 & \\
\hline \multirow{3}{*}{$\begin{array}{l}\text { Rainfall } \\
\text { (mm) }\end{array}$} & $579.34-623.25$ & 1 & \multirow{3}{*}{0.024} \\
\hline & $623.25-667.18$ & 2 & \\
\hline & $667.18-711.10$ & 3 & \\
\hline
\end{tabular}

stands for random index. RI depends on the number of factor that are used to perform AHP and in our case, for an 8 by 8 matrix, $R I=1.41$ (Saaty 1980), while $R I$ can be calculated by the following equation:

$$
C I=\frac{\lambda_{\max }-n}{n-1}
$$

In equation (5), $\lambda \max$ is the maximum eigenvalue of the comparison matrix and $\mathrm{n}$ is the number of factors. In the current study, $\lambda_{\max }=8.41$ and $n=8$, therefore $C R=0.042$. According to Saaty (1980), if $C R$ is less than 0.1 , then the weights' consistency is affirmed.

\subsubsection{Calculation of flood susceptibilityand} validation of the results

Finally, the data layers for each factor were added together in accordance with the mathematical equation (6):

$$
S=\sum_{i=1}^{n} w_{i} * X_{i}
$$

In equation (6), $S$ is the value for each pixel of the final flood susceptibility map of the study area, $\mathrm{w}_{\mathrm{i}}$ is the weigh for each factor and $X_{i}$ are the rating values for each pixel according to the factor to which it is referred.

The resulting susceptibility map was validated by calculating, with the aid of geoprocessing routines, the proportion of the inundated areas of the April 2017 and March 2018 flood events that intersected with its high susceptibility areas. This procedure indicated that $59 \%$ and $58 \%$ of the inundated areas of the 2018 and 2017 floods respectively coincided spatially with the high flood susceptibility zones of the resulting map.

\section{Results}

According to the results that were produced by flood extent mapping, the inundated areas within Erytropotamos' drainage basin, regarding the 2010 flood event, cover a total of $6.84 \mathrm{~km}^{2}$, while the inundated areas of the flood events that occurred on April 2017 and March 2018 cover a total extent of $18.23 \mathrm{~km}^{2}$ and $20.60 \mathrm{~km}^{2}$ respectively. The proportions of the inundated areas that were detected in open-land flooded areas and as shallow water in low vegetation areas are presented in more detail in Table 11.

Regarding susceptibility mapping, the resulting map was classified into three categories, which contained areas of high, medium, and low susceptibility (Figure 5). Moreover, the application of AHP methodology produced the criteria weight for each indicator. According to these results elevation was considered as the most important indicator with the weight value of 0.327 , followed by the slope angle with the weight value of 0.227 . Distance from stream and drainage density are respectively considered as the third and fourth most important criteria, and their weight values are 0.157 and 0.108 , respectively. The weights of the remaining indicators are below 0.1 , which indicates that they present less important than aforementioned four indicators. The criteria weight value of geology, land cover, TWI and rainfall are 0.073, 0.05, 0.034 and 0.024 , respectively (Tables 8 and 9).

Finally, by superimposing the delineated areas of the April 2017 and March 2018 inundation mapping onto the resulting susceptibility map, with the aid of geoprocessing routines, calculations indicated that the largest part of the aforementioned estimated flood

Tab. 11 Flood extents of the inundated areas for February 2010, April 2017 and March 2018 flood events.

\begin{tabular}{|l|c|c|c|}
\hline Flood event & $\begin{array}{c}\text { NDFI based } \\
\text { inundated area } \\
\left(\mathbf{k m}^{2}\right)\end{array}$ & $\begin{array}{c}\text { NDFVI based } \\
\text { inundated area } \\
\left(\mathbf{k m}^{2}\right)\end{array}$ & $\begin{array}{c}\text { Total } \\
\text { inundated area } \\
\left(\mathbf{k m}^{2}\right)\end{array}$ \\
\hline 2010 February & 6.49 & 0.35 & 6.84 \\
\hline 2017 April & 17.52 & 0.71 & 18.23 \\
\hline 2018 March & 19.28 & 1.32 & 20.60 \\
\hline
\end{tabular}




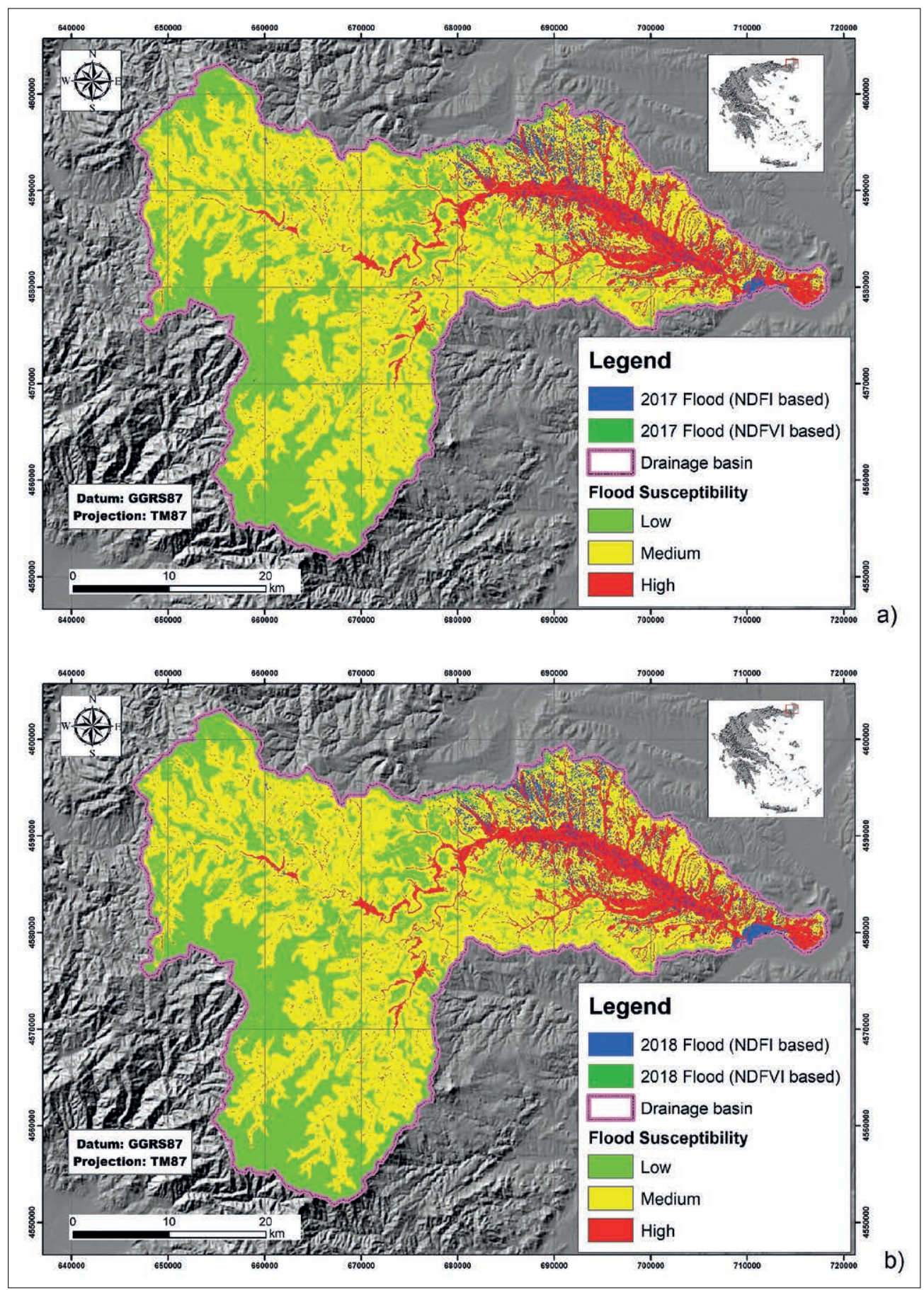

Fig. 5 Flood susceptibility map upon which are superimposed: a) the data layer of the April 2017 inundated areas (both NDFI and NDFVI based), and b) the data layer of the March 2018 inundated areas (both NDFI and NDFVI based).

extents coincided with the areas of high and medium susceptibility of the resulting map (Figure 5). Regarding the April 2017 flood, from the total of $18.23 \mathrm{~km}^{2}$ of the total inundated area in both open-land and in low vegetation, $10.6 \mathrm{~km}^{2}$ (58.17\%) intersected with the high flood susceptibility class. Additionally, high and medium susceptibility classes intersected with $17.54 \mathrm{~km}^{2}(96.22 \%)$ of the resulting flood extent. Correspondingly, from the total of $20.60 \mathrm{~km}^{2}$ of the March 2018 inundated area, $12.22 \mathrm{~km}^{2}$ (59.33\%) were included within the high flood susceptibility class, while high and medium susceptibility classes intersected with $19.73 \mathrm{~km}^{2}$ (95.8\%) of the resulting flood extent (Table 12).

\section{Discussion}

By comparing the flood extents of the flood events, it appeared that the inundated areas of 2010 are considerably smaller than the inundated areas of 2018 and 2017. The 2010 flood covered an extent of $6.84 \mathrm{~km}^{2}$, 
Tab. 12 Area extent and percentage of the part of the March 2018 and April 2017 inundated areas, which intersect with high to medium classes of the susceptibility map.

\begin{tabular}{|c|c|c|}
\hline Flood susceptibility classes & $\begin{array}{l}\text { Inundated area } \\
\qquad\left(\mathrm{km}^{2}\right)\end{array}$ & $\begin{array}{c}\text { Percentage } \\
\text { (\%) }\end{array}$ \\
\hline \multicolumn{3}{|l|}{2018 March flood } \\
\hline High & 12.22 & 59.33 \\
\hline High and medium & 19.73 & 95.80 \\
\hline \multicolumn{3}{|l|}{2017 April flood } \\
\hline High & 10.60 & 58.17 \\
\hline High and medium & 17.54 & 96.22 \\
\hline
\end{tabular}

in comparison with the inundated areas of the 2017 and 2018 flood events, which covered areas of 18.23 $\mathrm{km}^{2}$ and $20.60 \mathrm{~km}^{2}$ respectively; however, as it was mentioned earlier, validation of these results was not feasible due to unfavourable weather conditions. At first place, these differences in flood extents might indicate that the 2010 flood had probably a lower return period than the other two flood events. Furthermore, it is worth mentioning that according to the gauging station on Didymoteicho's bridge, the 2010 flood reached a peak discharge of $1,255.05 \mathrm{~m}^{3} / \mathrm{s}$, while, on the other hand, such gauges were not available for the 2017 and 2018 floods.

Regarding the uncertainties that exist in flood inundation mapping with the use of Remote Sensing and especially SAR, it has to be mentioned that such techniques and methodologies suffer mostly from speckle and from under or over-detection of flood extents especially in urban and vegetated areas. Currently there is no methodology that can overcome these difficulties entirely. However, flood inundation mapping is still considered appropriate for validation in cases of flood susceptibility and flood hazard mapping. (Giustarini et al. 2015a; Giustarini et al. 2015b; Schumann et al. 2015)

Concerning flood susceptibility mapping, there is a wide variety of works that utilize the AHP methodology for its implementation. The main differences and similarities of these works with the present research focus on the following points: 1 ) the factors that are employed by the research, 2) the determination of the importance between the factors that are used by the AHP procedure, 3 ) the dominant flood susceptibility factors of the study area and 4) the validation of the resulting flood susceptibility map.

The number and type of factors that are used in order to determine the spatial distribution of flood susceptibility, with the use of AHP, depend heavily on data availability (Xiao et al. 2018; Zhao et al. 2018). However, it can be observed that certain factors such as elevation, slope angle, land cover, lithology and distance from streams are used in the vast majority of works due to being easily produced via Digital Elevation Models (DEMs), geological maps and the various Corine Land Cover data layers. Other factors such as TWI (Arabameri et al. 2019; Das 2018; Tang et al. 2018), flow accumulation (Vojtek et al. 2019; Das 2018; Mahmoud et al. 2018; Kazakis et al. 2015), drainage density (Arabameri et al. 2019; Souissi et al. 2019; Vojtek et al. 2019; Das 2018; Mahmoud et al. 2018; Seejata et al. 2018) and rainfall (Souissi et al. 2019; Mahmoud et al. 2018; Seejata et al. 2018; Tang et al. 2018; Kazakis et al. 2015) appear in most works. On the contrary, curvature (Arabameri et al. 2019; Das 2018), NDVI (Normalized Difference Vegetation Index) (Arabameri et al. 2019), runoff/CN (Curve Numbers) (Vojtek et al. 2019; Mahmoud et al. 2018), SPI (Stream Power Index) (Arabameri et al. 2019) and groundwater depth (Souissi et al. 2019) appear rarely on flood susceptibility mapping works. Moreover, the number of the factors that are used in flood susceptibility mapping varies greatly (Mahmoud et al. 2018; Rahmati et al. 2015) with the most common number of factors ranging from seven to nine.

This paper tries to employ the most common and important factors that can be used in flood susceptibility mapping. Thus, flow accumulation was not included, since its data layer was indirectly employed by the TWI factor. Likewise, Stream Power Index (SPI) and Sediment Transport Index (STI) were not utilized because, according to Miliaresis (2006), these are, like TWI, indices of soil erosion with very similar mathematical expressions and thus they produce similar results. Curvature is considered to have a minor impact on the occurrence of a flood (Das 2018) and therefore it was not included in the factors that were utilized in the assessment of flood susceptibility. Additionally, Topographic position index (TPI) and Topographic roughness index (TRI) are rarely used in flood susceptibility mapping and even more rarely appear to be more important than the factors with which they are compared, so they were too omitted. Finally, the curve numbers (CN) data layer was not feasible to be compiled since there were no available maps depicting the spatial distribution of the hydrological soil groups.

The determination of the importance between the factors that are used in AHP when conducting flood susceptibility mapping can be achieved by applying various procedures. Many researches use sensitivity analysis in order to overcome the subjectivity of AHP (Souissi et al. 2019; Mahmoud et al. 2018; Tang et al. 2018), while weight linear combination is also a popular approach (Vojtek et al. 2019; Kazakis et al. 2015). There is also a great number of works that employ expert opinion in dealing with the hierarchy of factors (Das 2018; Seejata et al. 2018; Rahmati et al. 2015). However, the current trend involves the use of training algorithms over a part of the elements that will be used for the validation of the resulting susceptibility map, which usually involves a database of historical points where floods occurred (Arabameri et al. 2019). The present paper is introducing the use of the results of SAR-based inundation mapping, of a confirmed via gauges flood event, in the determination of the 
importance of the factors that affect flood susceptibility in AHP. Specifically, the aforementioned hierarchy was determined according to the part of the extent of the inundated area of the 2010 flood that intersected with each factor's highest susceptibility class, thus overcoming the subjectivity of AHP.

When it comes to the determination of the most important factor in flood susceptibility mapping, the results of AHP in various researches indicate that there is no factor to have clear dominance over other factors. Many papers indicate slope angle as the most important factor (Arabameri et al. 2019; Vojtek et al. 2019), while flow accumulation (Kazakis et al. 2015), elevation (Souissi et al. 2019) or even rainfall (Seejata et al. 2018) have been determined as the dominant flood susceptibility factors in certain regions and by certain methodologies. Likewise the present research determined elevation as the most important flood susceptibility factor, but it can be observed that the results depend heavily on both the procedure that is employed in the determination of the hierarchy of factors and the conditions that lie within the studied region.

Regarding the validation of the results of flood susceptibility mapping with the use of AHP, the vast majority of works involves the compilation of a historical database that includes, in the form of points, sites where according to eye-witnesses or Remote Sensing techniques floods occurred (Arabameri et al. 2019; Souissi et al. 2019; Vojtek et al. 2019; Mahmoud et al. 2018). The present work handles this matter by utilizing the results of SAR-based inundation mapping for specific flood occurrences. To this end, the inundated areas of the 2017 and 2018 floods, which were not involved in the determination of the importance between the factors in AHP, were used in order to provide the proportions of their respective flood extents that intersected with the high flood susceptibility zones of the resulting map. Furthermore, the resulting flood susceptibility map (Figure 5), indicated that the areas of high susceptibility are located on the eastern part of the study area, specifically in the first half of main stream and appear increased toward the basin mouth.

Moreover, the scores that were achieved by the validation of the susceptibility map were quite high. In particular, approximately $60 \%$ of the inundated areas from the April 2017 and March 2018 floods intersect with the high susceptibility zones of the map. The percentage rises to approximately $96 \%$ in the case that the aforementioned inundated areas intersect with the map's high to moderate susceptibility zones.

Finally, it is worth mentioning that the source data layers of the factors that were used in flood susceptibility mapping, in terms of scale and spatial resolution, were quite consistent since the majority of them were derived from EU-DEM that has a spatial resolution of $25 \mathrm{~m}$. The data layers of geology and Corine Land Cover 2012 involved a smaller scale, while the data layer of rainfall had to be downscaled in order to reach the spatial analysis of the EU-DEM data layer. However, the aforementioned spatial variations of these data layers do not appear to have a significant effect on the resulting susceptibility map since they were ranked among the least important flood susceptibility factors (Table 10). Additionally, the extent of the study area involved a considerably large drainage basin, which, in terms of size, allowed the use of small scale data, which are widely used in likewise cases according to the existing literature regarding AHP flood susceptibility mapping (Kazakis et al. 2015).

\section{Conclusions}

The present research paper introduced the idea to use the extent of a flood that has been captured by SAR imagery in order to determine the importance between flood susceptibility factors and thus dealing with the subjectivity that involves the determination of the hierarchy of factors in AHP. The larger the part of the inundated area that intersects with the factor's high susceptibility zone, the more important the factor is considered over the others.

According to the results of the applied methodology, elevation was found to be the most dominant flood susceptibility factor in the catchment of Erythropotamos. However, this has to be further ascertained by considering more future flood events in the same area and by taking advantage of the current and prospective availability of SENTINEL-1 imagery data. Moreover, the resulting susceptibility map appeared to be in consistency with the, April 2017 and March 2018 flood extents, since the aforementioned inundated areas coincided mostly with the high flood susceptibility class of the resulting map.

It appears that the suggested methodology, regarding the determination of the hierarchy of flood susceptibility factors, via the results of SAR-based inundation mapping, in AHP produced some interesting results. Nevertheless, more thorough testing of this proposed methodology is required, while it also remains to be seen if its application on other drainage basins shall indicate each time another factor as more prevalent in flood susceptibility, thus maintaining the argument that the conditions that affect flood susceptibility are unique for each catchment.

\section{References}

Arabameri, A., Rezaei, K., Cerdà, A., Conoscenti, C., Kalantari, Z. (2019): A comparison of statistical methods and multi-criteria decision making to map flood hazard susceptibility in Northern Iran. Science of the Total Environment 660, 443-458, https://doi.org/10.1016 /j.scitotenv.2019.01.021. 
Astaras, T., Oikonomidis, D., Mouratidis, A. (2011): Psifiakí Chartografía kai Geografiká Systímata Pliroforión [Digital Cartography and GIS]. Thessaloniki: Ekdóseis Dísigma [Disigma Publishing Group].

Beven, K., Kirkby, M. (1979): A Physically Based, Variable Contributing Area Model of Basin Hydrology. Hydrological Science Bulletin 24, 43-69, https://doi .org/10.1080/02626667909491834.

Birkholz, S., Muro, M., Jeffrey, P., Smith, H. M. (2014): Rethinking the relationship between flood risk perception and flood management. Science of the Total Environment 478, 12-20, https://doi.org/10.1016 /j.scitotenv.2014.01.061.

Chen, Y., Liu, R., Barrett, D., Gao, L., Mingwei, Z., Renchullo, L., Emelyanova, I. (2015): A spatial assessment framework for evaluating flood risk under extreme climates. Science of the Total Environment 538, 512-523, http://dx.doi.org/10.1016/j.scitotenv 2015.08.094.

Chen, Y., Yu, J., Khan, S. (2013): The spatial framework for weight sensitivity analysis in AHP-based multi-criteria decision making. Environmental Modelling and Software 48, 129-140, https://doi.org/10.1016/j.envsoft.2013 .06 .010 .

Cian, F., Marconcini, M., Ceccato, P. (2018). Normalized Difference Flood Index for rapid flood mapping: Taking advantage of EO big data. Remote Sensing of Environment 209, 712-730, https://doi.org/10.1016 /j.envsoft.2013.06.010.

CoG (Committee of Geology) (1989). Geologic map of P.R. Bulgaria, Scale 1:50 000.

COPERNICUS, Europe's eyes on earth - land monitoring service. Available online: https://land.copernicus.eu /pan-european/corine-land-cover/clc-2012?tab =download (accessed on 25/11/2017).

COPERNICUS, Europe's eyes on earth - land monitoring service. Available online: https://land.copernicus.eu /pan-european/corine-land-cover/ clc2018 (accessed on $17 / 4 / 2020$ ).

Costache, R., Pham, Q. B., Sharifi, E., Linh, N. T. T., Abba, S. I., Vojtek, M., Vojteková, J., Nhi, P. T. T., Khoi, D. N. (2020): Flash-Flood Susceptibility Assessment Using Multi-Criteria Decision Making and Machine Learning Supported by Remote Sensing and GIS Techniques. Remote Sensing 12(1), 106, https://doi.org/10.3390 /rs12010106.

Das, S. (2019): Geographic information system and AHP-based flood hazard zonation of Vaitarna basin, Maharashtra, India. Arabian Journal of Geosciences 11, 576, https://doi.org/10.1007/s12517-018-3933-4.

Demek, J. (1972). Manual of detailed geomorphological mapping. Academia, Prague.

Dikau, R. (1989): The application of a digital relief model to landform analysis. In: J. F. Raper, ed. Three Dimensional Application in Geographical Information Systems. Taylor and Francis, London, 51-77.

European Environment Agency (EEA) (2017):

Copernicus Land Monitoring Service -

EU-DEM. Published 7/12/2017 from: https:// www.eea.europa.eu/data-and-maps/data/ copernicus-land-monitoring-service-eu-dem.

Ettinger, S., Mounaud, L., Magill, C., Yao-Lafourcade, A.-F., Thouret, J.-C., Manville, V., Negulescu, C., Zuccaro, G., De Gregorio, D., Nardone, S., Uchuchoque, J.A.L.,
Arguedas, A., Macedo, L., Llerena, N. M. (2016): Building vulnerability to hydro-geomorphic hazards: estimating damage probability from qualitative vulnerability assessment using logistic regression. Journal of Hydrology 541, 563-581, https://doi.org/10.1016 /j.jhydrol.2015.04.017.

Fick, S. E., Hijmans, R. J. (2017): Worldclim 2: New 1-km spatial resolution climate surfaces for global land areas. International Journal of Climatology 37(12), 4302-4315, https://doi.org/10.1002/joc.5086.

Giustarini, L., Chini, M., Hostache, R., Pappenberger, F., Matgen, P. (2015a). Flood hazard mapping combining hydrodynamic modeling and multi annual remote sensing data. Remote Sensing 7(10), 14200-14226, https://doi.org/10.3390/rs71014200.

Giustarini, L., Vernieuwe, H., Verwaeren, J., Chini, M., Hostache, R., Matgen, P., Verhoest, N.E.C. De Baets, B. (2015b): Accounting for image uncertainty in SAR-based flood mapping. International Journal of Applied Earth Observation and Geoinformation 34, 70-77, https://doi .org/10.1016/j.jag.2014.06.017.

Hong, H., Panahi, M., Shirzadi, A., Ma, T., Liu, J., Zhu, A-X., Chen, W., Kougias, I., Kazakis, N. (2018): Flood susceptibility assessment in Hengfeng area coupling adaptive neuro-fuzzy inference system with genetic algorithm and differential evolution. Science of the total Environment 621, 1124-1141, https://doi.org /10.1016/j.scitotenv.2017.10.114.

I.G.M.E. (Institute of geology and mineral exploration) (2002): Synoptic geologic map of SE Rhodope - Thrace, Scale 1:200 000, Xanthi.

Kanani-Sadat, Y., Arabsheibani, R., Karimipour, F., Nasseri, M. (2019): A new approach to flood susceptibility assessment in data-scarce and ungauged regions based on GIS-based hybrid multi criteria decision-making method. Journal of Hydrology 572, 17-31, https:// doi.org/10.1016/j.jhydrol. 2019.02.034.

Kazakis, N., Kougias, I. Patsialis, T. (2015): Assessment of flood hazard areas at a regional scale using an index-based approach and Analytical Hierarchy Process: application in Rhodope-Evros region, Greece. Science of the Total Environment 538, 555-563, https:// doi.org/10.1016/j.scitotenv.2015.08.055.

Khosravi, K., Nohani, E., Maroufinia, E., Pourghasemi, H. R. (2016): A GIS-based flood susceptibility assessment and its mapping in Iran: a comparison between frequency ratio and weights-of-evidence bivariate statistical models with multi-criteria decision-making technique. Natural Hazards 83, 947-978, https://doi.org/10.1007 /s11069-016-2357-2.

Li, J., Heap, A. (2014): Spatial interpolation methods applied in the environmental sciences: A review. Environmental Modelling and Software 53, 173-189, https://doi.org /10.1016/j.envsoft.2013.12.008

Li, Y., Martinis, S., Plank, S., Ludwig, R. (2018): An automatic change detection approach for rapid flood mapping in Sentinel-1 SAR data. International Journal of Applied Earth Observation and Geoinformation 73, 123-135, https://doi.org/10.1016/j.jag.2018.05.023.

Long S., Fatoyinbo, T. E., Policelli, F. (2014): Flood extent mapping for Namibia using change detection and thresholding with SAR. Environmental Research Letters 9, 35002-35009, https://doi.org/10.1088 /1748-9326/9/3/035002. 
Lyu, H. M., Sun, W. J., Shen, S. L., Arulrajah, A. (2018): Flood risk assessment in metro systems of mega-cities using a GIS-based modeling approach. Science of the Total Environment 626, 1012-1025, https://doi.org /10.1016/j.scitotenv.2018. 01.138.

Mahmoud, S., Gan, T. Y. (2018): Multi-criteria approach to develop flood susceptibility maps in arid regions of Middle East. Journal of Cleaner Production 196, 216-229, https://doi.org/10.1016/j.jclepro.2018 .06 .047 .

Matgen, P., Hostache, R., Schumann, G. J. P., Pfister, L., Hoffmann, L. Savenije, H. H. G. (2011): Towards an automated SAR-based flood monitoring system: lessons learned from two case studies. Physics and Chemistry of the Earth 36 (7-8), 241-252, https://doi.org/10 .1016/j.pce.2010.12.009.

Miliaresis A. (2006). Eidikés Efarmogés sto AcGIS. [Specialized applications in ArcGIS]. Ekdóseis «ION» [ION Publishing Group], Athens.

Mouratidis A. (2011): Contribution of Earth Observation data and GIS to mapping and managing flood evens in Greece. Final Report of "GEOGIS floods" research project funded by the John S. Latsis Public Benefit Foundation.

Mouratidis, A., Ampatzidis, D. (2019): European Digital Elevation Model (EU-DEM) validation against extensive Global Navigation Satellite Systems data and comparison with SRTM and ASTER-GDEM in Central Macedonia (Greece). ISPRS, International Journal of Geo-Information 8(3), 108, https://doi.org/10.3390 /ijgi8030108.

Mouratidis, A., Nikolaidou, M., Doxani, G., Lampiri, M., Sarti, F. Tsakiri-Strati, M. (2011): Flood studies in Greece using Earth Observation data and Geographical Information Systems. Geological Remote Sensing Group (GRSG) Annual General Meeting, 7-9 December 2011, ESA /ESRIN, Frascati, Italy.

Mouratidis, A., Sarti, F. (2013): Flash-Flood Monitoring and Damage Assessment with SAR Data: Issues and Future Challenges for Earth Observation from Space Sustained by Case Studies from the Balkans and Eastern Europe. In: Krisp J., Meng L., Pail R., Stilla U., eds. Earth Observation of Global Changes (EOGC). Lecture Notes in Geoinformation and Cartography. Springer, Berlin, Heidelberg, 125-136, https://doi. org/10.1007/978-3-642-32714-8_8.

Nandi, A., Mandal, A., Wilson, M., Smith, D. (2016). Flood hazard mapping in Jamaica using principal component analysis and logistic regression. Environmental Earth Sciences 75, 465, https://doi.org/10.1007 /s12665-016-5323-0.

Nikolaidou, M., Mouratidis, A., Doxani, G., Oikonomidis, D., Tsakiri-Strati, M., Sarti, F. (2015): An on-line flood database for Greece supported by Earth Observation data and GIS. Proceedings of the 10th International Congress of the Hellenic Geographical Society, 22-24 October 2014, Thessaloniki, Greece, 671-688.

Papaioannou, G., Vasiliades, L., Loukas, A. (2015): Multi-criteria analysis framework for potential flood prone areas mapping. Water Resoures Management 29, 399-418, http://dx.doi.org/10.1007/s11269-014 $-0817-6$.

Patrikaki, O., Kazakis, N., Kougias, I., Patsialis, T., Theodosiou, N. Voudouris, K. (2018): Assessing flood hazard at river basin scale with an index-based approach: The case of Mouriki, Greece. Geosciences 8(50), 1-13, https://doi.org/10.3390 /geosciences8020050.

Pierdicca, N., Pulvirenti, L., Chini, M., Guerriero, L. Candela, L. (2013): Observing floods from space: Experience gained from COSMO-SkyMed observations. Acta Astronautica 84, 122-133, http://dx.doi.org/10.1016 /j.actaastro. 2012.10.034.

Psomiadis, E. (2016): Flash flood area mapping utilising SENTINEL-1 radar data. Proceedings of SPIE, 10005, https://doi.org/10.1117/12.2241055.

Pulvirenti, L., Pierdicca, N., Chini, M., Guerriero, L. (2011): An algorithm for operational flood mapping from Synthetic Aperture Radar (SAR) data using fuzzy logic. Natural Hazards and Earth System Sciences 11, 529-540, https://doi.org/10.5194/nhess-11-529-2011.

Rahmati, O., Zeinivand, H., Besharat, M. (2015): Flood hazard zoning in Yasooj region, Iran, using GIS and multi-criteria decision analysis. Geomatics, Natural Hazards and Risk 7(3), 1000-1017, https://doi.org /10.1080/19475705.2015.1045043.

Saaty, T. L. (1980): The Analytic Hierarchy Process. McGraw-Hill, New York.

Schlaffer, S., Matgen, P., Hollaus, M. Wagner, W. (2015): Flood detection from multi-temporal SAR data using harmonic analysis and change detection. International Journal of Applied Earth Observation and Geoinformation 38, 15-24, http://dx.doi.org/10.1016/j.jag.2014.12.001.

Schumann, G. J. P., Moller, D. K. (2015): Microwave remote sensing in flood inundation. Physics and Chemistry of the Earth 83-84, 84-95, https://doi.org/10.1016/j.pce .2015.05.002.

Seejata, K., Yodying, A., Wongthadam, T., Mahavik, N., TantaneE, S. (2018): Assessment of flood hazard areas using Analytical Hierarchy Process over the Lower Yom Basin, Sukhothai Province. Procedia Engineering 212, 340-347, https://doi.org/10.1016/j.proeng.2018 .01 .044 .

Souissi, D., Zouhri, L., HammamI, S., Msaddek, M. H., Zghibi, A., Dlala, M. (2019): GIS-based MCDM - AHP modelling for flood susceptibility mapping of arid areas, southeastern Tunisia. Geocarto International, https:// doi.org/10.1080/10106049.2019.1566405.

Stefanidis, S., Stathis, D. (2013): Assessment of flood hazard based on natural and anthropogenic factors using analytic hierarchy process (AHP). Natural Hazards: Journal of the International Society for the Prevention and Mitigation of Natural Hazards, Springer; International Society for the Prevention and Mitigation of Natural Hazards 68, 569-585, https:// doi.org/10.1007/s11069-013-0639-5.

Tang, Z., Zhang, H., Yi, S., Xiao, Y. (2018): Assessment of flood susceptible areas using spatially explicit, probabilistic multi-criteria decision analysis. Journal of Hydrology 558, 144-158, https://doi.org/10.1016 /j.jhydrol.2018.01.033.

Tehrany, M. S., Pradhan, B., Jebur, M. N. (2014): Flood susceptibility mapping using a novel ensemble weightsof-evidence and support vector machine models in GIS. Journal of Hydrology 512, 332-343, https://doi.org /10.1016/j.jhydrol.2014.03.008.

Tehrany, M. S., Pradhan, B., Mansor, S., Ahmad, N. (2015): Flood susceptibility assessment using GIS-based support vector machine model with different kernel types. 
Catena 125, 91-101, https://doi.org/10.1016/j.catena .2014.10.017.

Vieux, B. E. (2004). Distributed Hydrologic Modelling using GIS. Kluwer Academic Publishers, Netherlands, 123-124.

Voudouris, K., Mavrommatis, T. Antonakos, A. (2007): Hydrologic balance estimation using GIS in Korinthia prefecture, Greece. Advances in Science and Research 1, 1-8, https://doi.org/10.5194/asr-1-1-2007.

Vojtek, M., Vojteková, J. (2019): Flood Susceptibility Mapping on a National Scale in Slovakia Using the Analytical Hierarchy Process. Water 11, 364, https:// doi.org/10.3390/w11020364.

Wang, Y., Hong, H., Chen, W., Li, S., Pamucar, D., Gigovic, L., Drobnjak, S., Bui, D. T., Duan, H. (2019): A Hybrid GIS Multi-Criteria Decision-Making Method for Flood Susceptibility Mapping at Shangyou, China. Remote Sensing, 11, 62, https://doi.org/10.3390/rs11010062.

Wang, Y., Li, Z. Tang, Z. (2011): A GIS-based spatial multi-criteria approach for flood risk assessment in the Dongting Lake Region, Hunan, Central China. Water Resources Management 25, 3465-3484, https:// doi.org/10.1007/s11269-011-9866-2.

Xiao, Y., Yi, S., Tang, Z. (2018): Integrated flood hazard assessment based on spatial ordered weighted averaging method considering spatial heterogeneity of risk preference. Science of the Total Environment 599-600, 1034-1046, https://doi.org/10.1016/j.scitotenv .2017.04.218.

Yésou, H., Sarti, F., Tholey, N., Mouratidis, A., Clandillon, S., Huber, C., StudeR, M., De Fraipont, P. (2013): Addressing emergency flood mapping and monitoring of inland water bodies with sentinel 1-2. Expectations and perspectives. Living Planet Symposium, 9-13 September 2013, Edinburgh, UK, ESA SP-722.

Zhao, G., Pang, B., Xu, Z., Yue, J., Tu, T. (2018): Mapping flood susceptibility in mountainous areas on a national scale in China. Science of the Total Environment 615, 1133-1142, https://doi.org/10.1016/j.scitotenv .2017.10.037.

Zhong, S., Yang, L., Toloo, S., Wang, Z., Tong, S., Sun, X., Crompton, D., Fitzgerald, G., Huang, C. (2018): The long-term physical and psychological health impacts of flooding: A systematic mapping. Science of the Total Environment 626, 165-194, https://doi.org/10.1016 /J.SCITOTENV.2018.01.041.

Zhou, Z., Psomiadis, E., Dercas, N. (2014): Analysis of the drainage density of experimental and modelled tidal networks. Earth Surface Dynamics 2, 105-116, https:// doi.org/10.5194/esurf-2-105-2014. 